\title{
ENSURING SUPPLIES OF MEDICINES DURING PANDEMICS IN TERMS OF PUBLIC PROCUREMENT
}

\section{Vít Vlček}

Central Institute for Supervising and Testing in Agriculture, Brno, Czech Republic

\section{SUMMARY}

Objectives: This article describes and comments on contemporary legal regulations concerning the supply of medicines during pandemics in terms of public procurement.

Methods: Suggestions are made for removing existing legislative shortcomings, clarifying the diction of existing laws or rendering precision to legal regulation of public procurement given purchases of medicines during periods of imminent threats of pandemics and duration of pandemics.

Results: The author reflects on improving legislation concerning the lack of clarity and the doubts concerning the contemporary legal order of the Czech Republic, with reference to speeding up and simplifying public procurement procedures for incident-free purchases of necessary medicines in time of pandemic crisis situation and then effectively supporting the struggle against any pandemic infection.

Conclusion: The issues raised should be addressed since better legislation can significantly contribute to the containment of pandemics and their consequences for individual and public health.

Key words: public procurement, medicines, legal causes of systemic shortcomings, negotiated procedure without prior publication, pandemic

\section{Address for correspondence: V. Vlček, Pod Kaštany 245/10, 16000 Praha 6, Czech Republic. E-mail: vitvlcek@seznam.cz}

https://doi.org/10.21101/cejph.a5150

\section{INTRODUCTION}

The present text ponders over ensuring the right of health protection in pandemics or pandemic threats from the point of view of the timely procurement of medicines. In view of Article 31 of the Constitutional Charter on Fundamental Rights and Freedoms (2/1993 Coll.), which establishes the constitutional right of health protection, it should be considered whether the present wording of the Czech legal order ensures sufficient fulfilling of that constitutional right under the above mentioned health crisis situation with respect to procurement of medicines required for protection in general and those affected in particular $(1,2)$.

The text deals with an assumed situation caused by a vast epidemic or pandemic when in the public interest it is necessary to supply an adequate amount of medicines in bulk.

Epidemics and pandemics are transitional in nature, affecting transnational areas. In view of these epidemiological characteristics of such a disease occurrence, shortcomings in supplies of vaccines and medicines in need have been revealed in connection with the pandemic influenza of 2009, in which the mechanisms of the EU in respect of the above were guided by the existing procedures for procurement of vaccines and medicines: "Joint Procurement Agreement to Procure Medical Countermeasures", signed in 2014, to improve their preparedness when countering border threats.

This agreement is based on the Decision of the European Parliament and of the Council Decision No. 1082/2013/EU of the European Parliament and of the Council of 22 October 2013 on serious cross-border threats to health and Decision No. 2119/98/EC.

There is evidently a public health crisis within the EU, which no single EU member state is capable to deal with itself.
Interpretative disputes cannot be ruled out where the procedure in order to protect life and health may come into conflict with the rules of fair competition. One could assume that the protection of human life and health is an absolute priority and therefore any such conflicts are out of the question. In theory, such disputes are inadmissible although in practice the situation is often different; in some cases, it is a question of whether regular procurement procedure should be applied due to the time required for realisation of normal competition. For this reason, it is necessary to mention crisis management. Crisis management in the Czech Republic is governed by the rule of the highest legal force, i.e. the Constitutional Act 110/1998 Coll. on the security of the Czech Republic (3). This Act provides for the government declaring a state of emergency in the event of natural disasters, environmental or industrial accidents, accidents or another danger that endanger lives, health or property, or internal order and security. In fact, the state of emergency has been so far declared only for floods and storms.

It can be assumed that a pandemic could be considered as another danger that, to a great extent, endangers lives and health of the population.

Emergency status is announced for a maximum of 30 days, for a longer period of time with the consent of the Government. Therefore, it can be concluded that the Constitutional Act of the Czech Republic could, by declaring a state of emergency, allow the use of Crisis Act 240/2000 Coll. This Act provides that such a procedure would only be possible for a limited time. This is covered by the Act No.134/2016 Coll. on Public Procurement.

This provision could allow the purchase of medicines without legal restrictions. But there is no example or precedent for such 
a procedure. In any case, the procedure could be applied for a very limited time.

It can be assumed that in the event of an emergency medical crisis, the Ministry of Health should be the authority responsible for the enforcement of all activities related to this legal Act.

In view of the questionability or controversy of such a procedure, its time constraints, economic risk, and no experience with such a procedure, the article does not further address this theoretical possibility of purchasing medicines. The article also deals with legal procedures.

Sometimes it is questionable whether it is appropriate or necessary to purchase the necessary medicines outside the regular legal process; such a procedure is enabled by special provision of the Act 134/2016 Coll. on Public Procurement (4). In this sense, we are dealing with the purchase of goods for which the purchase price changes throughout the financial year. If a given regular procedure is legally possible it becomes mandatory. A different procedure is then viewed in fraudem legis or contra legem.

\section{Summary of Problems}

As regards the Czech legislation, it should be noted that according to Section 49 of the Act on Protection of Public Health 258/2000 Coll., in its current wording, vaccines for special and extraordinary vaccinations are paid from the state budget (5).

The following is the summary of public purchasing problems:

- Very urgent circumstances are not defined.

- It should be defined if the circumstances are or are not a defence matter.

- Possibility of using generic drugs under the Act on Pharmaceuticals 378/2007 Coll.

- Prompt granting of a compulsory licence according to the Act 527/1990 Coll. on inventions and improvement proposals.

- Public procurement in terms of timeliness and legal options for an imminent flu pandemic.

- Procedure rules:

- negotiation without prior publication with multiple suppliers;

- negotiation without prior publication of a single supplier for reasons of urgency.

- Negotiated procedure with publication with multiple suppliers.

- Free competition and free movement of goods.

- Matter of patent protection.

- Political decision-making from the point of view of the prevention of epidemics or pandemics in the supply of medicines.

The definition of urgent circumstances required by the Act 134/2016 Coll., on Public Procurement is missing. To legitimize the possibility of a quick and immediate purchase of medicines, such a definition is definitely necessary. Otherwise, such a definition must be created by the procurement authority itself and may result in serious legal disputes and suspicion of infringements (8-13).

It is not determined whether the pandemic is a matter of defence. The issue should be resolved in accordance with the relevant provisions of the above Act. Therefore, the matter should not be dealt with under the provisions relating to defence and security; however, in case of an escalated military situation a pandemic could be considered a matter of defence, with respect to possible impact on the armed forces.

There is possibility of a rapid decision on the use of generics under the Act No. 378/2007 Coll. on Pharmaceuticals, in the cur- rent version $(6,7)$. If the use of generics corresponds to the law, this should not present a problem.

The accelerated granting of a compulsory license is a process according to Section 20 of the Act No. 527/1990 Coll. on Inventions and Improvement Proposals in the current version. If the patentee prevents the use of a patented drug, such a situation can be successfully addressed by the above-mentioned Act.

There should be specific options for the use of open procedure for pharmaceuticals with long expiration terms and predictability related to the scope and origin of the epidemic. In the event that medicines will last then the open procedure for such medicines is optimal for their procurement. The problem may be an obstacle to patent protection by Act No. 527/1990 Coll. on Inventions and Improvement Proposals, especially for newer medicines. In case of medicines with a long history of use, the competition of generics presents a viable opportunity. In this area, we must bear in mind that on the one hand, it is necessary to proceed efficiently in terms of spending budget funds in compliance with the rules of free competition, but on the other hand to ensure timely supply of enough drugs for the protection of lives and health as an absolute priority. With regard to the expiration of medicines, this is expected only with limited stockpiling of drugs.

The likelihood of a pandemic should be taken into account when ordering medical supplies. The most likely scenario is the emergence of an influenza pandemic where the incubation period is 18-24 hours, sometimes up to 72 hours. In each case, the disease spreads very quickly (14-18). The expiration period of antivirals is 5-7 years. This means that it is necessary to supply the drug to patients quickly, but in principle, it is possible to deliver drugs from stockpiles. The size of reserves is a matter of difficult calculations. Antiviral medicines have a market value of about 600 CZK to 1,500 CZK per pack. During the outbreak of Spanish Influenza, about 500 million persons from a world population of 1.8 billion were afflicted. Presently, it is possible to expect lower morbidity rates, but even today about $30 \%$ of the population could be affected. In the event of a pandemic of severe influenza with 1 million seriously ill inhabitants, the running costs for antiviral medication can reach billions of CZK. The political implications of stockpiling medical supplies should be taken into account because we know that a pandemic will occur, but do not know when. Further, for example, the estimated amount of vaccine for $20 \%$ of the population of the Czech Republic can cost about 0.6 billion CZK. Risk groups comprise citizens aged over 65 years, and those with chronic cardiovascular, respiratory tract, kidney or liver diseases, or diabetes, as well as patients with splenectomies and hematopoietic stem cell transplantation (HSCT), persons with congenital or acquired immune system dysfunctions, cystic fibrosis or chronic anaemia. There are also other groups of people for whom vaccinations are recommended such as pregnant women, persons who frequently come into contact with risk groups, physicians or social workers in plants, relatives of seriously ill patients, and employees working in larger teams (5). Therefore, approximately 2 million persons from the above population groups in the Czech Republic are likely to be affected at a cost of around 10 billion CZK (19). Vaccines and diagnostics must be provided flexibly because they cannot be stored in advance. In this context, case law and the Court of Justice of the European Union (CJEU) interpretation practice should be considered, although only under extremely urgent conditions (not merely urgent conditions). The 
difference between urgent and extremely urgent conditions is not defined. It would be better if at least this was defined in the Act, if only demonstratively. This implies the assumption that the legislature will be expected to use Negotiated Procedure without Prior Publication (NPWPP) limited to the first wave of deliveries for the first group of patients, followed by open procurement (4). In some cases, this will be possible from a medical point of view although as a consequence there may be problems of compatibility of various services such as clinical diagnostics, methodology or device settings. Certain supplies, such as antivirals, may be needed in large quantities, which are problematic due to their five-year expiry period. The unpredictable nature of pandemics makes the policy for management of these medicines markedly difficult.

The current Act No. 134/2016 Coll. in particular its provisions in accordance with relevant provisions (4), do not, in effect, deal with negotiated procedure without prior publication involving more than one supplier. Unlike the repealed Act no. 137/2006 Coll. determines that the authority of the written notice must determine: the method and principles of negotiations, if negotiations are with several interested parties, as well as in paragraph (3) which provides: in case of the negotiated procedure without prior publication with several economic operators, the contracting authority shall not disclose candidate information regarding the conditions and suggestions made without prior consent. The new legislation Act No. 134/2016 Coll. lacks any such provisions, which has all the hallmarks of a serious mistake. In the event of an imminent pandemic, a situation may arise in which negotiations with two or more suppliers is inevitable. In such a case the contracting authority comes up against vacuum legis: which may cause considerable and unsolvable problems.

The problem of urgency may arise, although the contracting authority should prove such urgency as a result of unpredictability. The implicit problem is, as discussed in literature, that the question is not if an influenza pandemic will occur, but when. In this the whole issue is analogous to insurance. An insurance company only insures unpredictable events, with the exception of life insurance, where death is inevitable but cannot be accurately predicted. By the same token, the predictability of pandemics should be viewed.

Theoretically, a situation may arise involving multiple vendors and there is no immediate danger of default, but the drug parameters have to be adjusted according to the client's requirements. In such a case the appropriate procedure would be in accordance with the relevant provision of the Act No. 134/2016 on public procurement in cases where the authority needs cannot be met without treatment of the provision. Here, in case of urgency, these periods can be shortened under the relevant provision of the Act 134/2016 Coll., for example, the deadline for submission of bids 10 days from receipt of a call by the contracting authority. Regarding the reduction of the period, the negotiated procedure with publication is useful, but only sometimes. Even with shorter deadlines the tender procedure may be too long for the timely delivery of medicines (4).

As mentioned above, where there is no need of supplying the medicines rapidly, and there are no legal obstacles presented by patent protection, it is necessary to select an open public procurement. In case of patent protection, NPWPP must be used according to the Act 134/2016 Coll. on Public Procurement: this is necessary for the protection of exclusive rights, including intellectual property rights. In urgent cases, the same section of the above Act should be used: the contracting authority may also use a negotiated procedure without prior publication, if necessary, due to extremely urgent circumstances that could not be foreseen and were not caused by the authority, without adequate time for open procedures, restricted procedures and procedures negotiated with publication. Free competition can also be restricted by a ban of re-exports. After expiry of legal protection, generics are often produced and supplied in lieu of the original patented medicines. The prices of these drugs vary from state to state. There is a risk that generics purchased in one country at a lower price will be distributed to other countries where they are for sale at a higher price. Thus, in a country where generics are cheaper, their availability can be limited or even non-existent. This is now prevented by the prohibition of redistribution with relevant legal sanctions under the Act No. 378/2007 Coll. on Pharmaceuticals, as amended by $66 / 2017$ Coll. The Ministry can forbid re-exportation by its action. Infringements can newly be penalized by a fine of up to 2 million CZK. The efficiency of this action has yet to be evaluated.

The following demands are placed on the State Institute for Drug Control (SIDC) of the Czech Republic and the professional medical community: if the original drug is irreplaceable, it is usually protected by patents; generic drugs cannot be marketed for a ten-year period from their first registration in any member state or the EU. For irreplaceable patent-protected drug purchases NPWPP is used, whereas in other cases patent protection should not be an obstacle.

In case of potential stockpiling it is necessary to take into account how much funding the government is willing to release. If the drugs are not urgently needed, it may be difficult to enforce release of additional budgetary funds in advance. In current political culture, where the norm is to spend budgetary funds for rapid electoral advantage, it is a question if appropriating funds for future medical preventive measures is at all possible.

\section{Appropriate Legislation}

The Act 134/2016 Coll., on Public Procurement, should by definition be amended in the event of extremely urgent circumstances, and ideally, in accordance with European legislation, very urgent circumstances should be defined.

This Act must necessarily be amended for situations involving essential negotiations without prior publication when dealing with more candidates, especially in terms of how the contracting authority shall deal with confidential information that it receives from the individual economic operators. Defining a pandemic or epidemic is also a matter of defence.

\section{CONCLUSION}

The proposed legislative amendments to the existing legal system are feasible. However, there is the question of policy concerning the stockpiling of the necessary drugs and preventive measures, especially vaccination, in the event of a pandemic threat. This issue is political, as stated above, and potentially sensitive. Possibly the only solution, albeit enforceable with difficulty, could be an amendment to the law on public health protection 258/2000 Coll. anchored in accordance with the Constitutional Charter 2/1993 Coll., the population and regular 
purchases of drugs for the whole population as a defence against possible pandemics. Harmonization of the Act 258/2000 Coll. on the Protection of Public Health with the Public Procurement Act 134/2016 Coll. would result in the concept of unpredictable urgency in both laws. It is, therefore, desirable that the necessity of unexpected and objectively unforeseeable purchases of drugs to treat pandemic situations is secured. This article could at least modestly challenge the further development of health legislation, health policy, and hence the need for the protection and promotion of public health.

\section{REFERENCES}

1. Svoboda P, Ondřejek P, Šustek P, et al. Philosophical and legal theoretical aspects of human rights. Prague: Charles University, Faculty of Law; 2013. (In Czech.)

2. Kosař D, Molek P, Honusková V, Jurman M, Lupačová H. Asylum act: commentary. Prague: Wolters Kluwer Czech Republic; 2010. (In Czech.)

3. Gerloch A. Theory of law. Dobrá Voda: Aleš Čeněk Publishing; 2000. (In Czech.)

4. Kruták T, Krutáková L, Gerych J. The Act on public procurement with commentary on October 1 2016. Olomouc: ANAG; 2016. (In Czech.)

5. Krýsa I, Krýsová Z. The Act on protection of public health: commentary. Prague: Wolters Kluwer Czech Republic; 2016. (In Czech.)

6. Král J. Pharmaceutical law. Prague: Erudikum; 2014. (In Czech.)

7. Šustek P, Holčapek T, et al. Health law. Prague: Wolters Kluwer Czech Republic; 2016. (In Czech.)
8. Bureš J, Drápal L, Krčmář Z, et al. Code of civil procedure: commentary. Prague: C. H. Beck; 2006. (In Czech.)

9. Jemelka L, Pondělíčková K, Bohadlo D. Code of administrative procedure: commentary. 2nd ed. Prague: C. H. Beck; 2009. (In Czech.)

10. Vedral J. Code of administrative procedure: commentary. 2nd ed. Prague: BOVA POLYGON; 2012. (In Czech.)

11. Jemelka L, Vetešník P, Libosvár O. Control act: commentary. Prague: C. H. Beck; 2014. (In Czech.)

12. Tuček M, et al. Hygiene and epidemiology. Prague: Karolinum; 2012. (In Czech.)

13. Pomahač R, Handrlica J. EU administrative law. Prague: C. H. Beck; 2012. (In Czech.)

14. Recommended actions before, during and after a pandemic. In: Pandemic influenza preparedness and response: a WHO guidance document. Geneva: WHO; 2009. p. 28-48.

15. Knobler SL, Mack A, Mahmoud A, Lemon SM. The Threat of pandemic influenza. Are we ready? Workshop summary. Washigton (DC): National Academies Press; 2005.

16. Rothstein MA. Should health care providers get treatment priority in an influenza pandemic? J Law Med Ethics. 2010;38(2):412-9.

17. National Strategy for Pandemic Influenza. Washigton (DC): Homeland Security Council; 2005.

18. Pandemic Influenza Plan: 2017 update. U. S. Department of Health and Human Services; 2017.

19. Eliáš K, et al. New civil code with updated explanatory report and index. Ostrava: Sagit; 2012. (In Czech.)

Received June 14, 2017 Accepted in revised form March 21, 2018 


\section{SUPPLEMENTS 2017}

\section{Supplement 1}

TRENDS IN HEALTH BEHAVIOUR IN CZECH SCHOOL-AGE CHILDREN: HBSC study.

The CEJPH Supplement evaluates the contribution of the Czech Republic to the cross-national Health Behaviour in School-aged Children (HBSC) study that is conducted in partnership with the World Health Organization. This cohort crosssectional questionnaire-based study is focusing on health and health-related behaviours in adolescents in the context of their social environment in their respective countries.

The main aim of the supplement is to provide evidence on various aspects of young people's health, wellbeing and related factors as found out in the Czech Republic over multiple survey years.

\section{Supplement 2}

DEVELOPMENT OF MORTALITY FROM NON-COMMUNICABLE DISEASES IN THE SLOVAK REPUBLIC AT NATIONAL AND REGIONAL LEVEL, ITS DETERMINANTS AND INTERNATIONAL COMPARISON

The CEJPH Supplement deals with the development of mortality from non-communicable diseases and its determinants in the Slovak Republic at national and regional level from 1996 to 2014, and it also offers international comparisons. 


\section{INSTRUCTION TO AUTHORS OF THE CENTRAL EUROPEAN JOURNAL OF PUBLIC HEALTH}

\section{Subject specialisation}

The Journal (CEJPH) publishes original articles on disease prevention and health protection, environmental impacts on health, the role of nutrition in health promotion, results of population health studies and critiques of specific health issues including intervention measures such as vaccination and its effectiveness. The review articles are targeted at providing up-to-date information in the sphere of public health. The Journal is geographically targeted at the European region but will accept specialised articles from foreign sources that contribute to public health issues also applicable to the European cultural milieu.

\section{General Information}

Manuscripts thematically relevant to the Journal's subject specialisation are to be submitted in digital form. Authors are requested to declare that their results have not been published previously, are not under submission elsewhere and that co-authors are cognizant of the submitted text and agree to its publication in CEJPH. By submitting a manuscript the author agrees to the above and the following instructions including publication fees.

Manuscripts should be addressed to the Editor-in-Chief's office, by email or contact form:

National Institute of Public Health

Central European Journal of Public Health

Šrobárova 48

10042 Prague 10, Czech Republic

Phone +420 267082 479, +420267082378

E-mail cejph@szu.cz

Following receipt of a manuscript and decision by the editorial board the corresponding author will be contacted regarding submission of the contribution into peer review proceeding or its rejection. All accepted contributions are reviewed, under conditions of mutual anonymity, by two independent reviewers. The author will be notified of the results of the review proceedings and requested to submit the final version of the manuscript.

The author is required to either accept reviewer comments or to substantiate refutal of the same, to make any proposed language changes in the text returned to the editorial board, unless successfully refuted, and to highlight any change made to the text.

The submission-to-publication period for manuscripts is approximately 24 months.

\section{Form of Manuscript}

Manuscripts are to be written in concise, carefully edited and linguistically adequate English. It must be typed with double-line spacing. Placement of figures, graphs and tables should only be indicated in the text, do not include it in the text as such.

Send contributions including all graphic documentation and declaration by the corresponding author, also including all figures, graphs and tables in original format attached. Text files are to be in Rich Text Format (.rtf) or MS Word (.doc, .docx). Do not formatting the text. Numbered tables and graphs (with legends) as well as figures in graphic formats (.tif or .jpg, for instance) will be in printable size and resolution min. $300 \mathrm{DPI}$.

\section{The manuscript should include:}

The title (first page) should carry the title of the paper (15 words or less), full names of authors in their native languages together with their respective institutional affiliation, and the name, address and email address of the author responsible for correspondence about the manuscript. The following pages contain a Summary complemented with 5-6 Keywords, Introduction, Material and Methods, Results, Discussion, Conclusions, Acknowledgements, statement of Conflict of Interests, sponsorship and adherence to ethical recommendations, associated grant projects, References, and Legends to figures and graphs. Summary, References in consecutive order according to their appearance in the text, and Legends to figures and graphs are to be written each on separate pages. The Summary at a maximum length of 300 words should be structured under the folloving headings: Objectives, Methods, Results, and Conclusions.

\section{Tables}

Kindly submit all tables in a separate file, one table per page. Number tables consecutively in the order of their first citation in the text with Arabic numerals and supply a brief title for each. Place explanatory matter in footnotes and explain all nonstandard abbreviations that are used in each table.

\section{Figures and Graphs}

Figures and graphs separate from the text files and apart from one another. Prepare your figures in a size suitable for reproduction. Titles and a detailed explanation should be indicated in the applicable legend. Source data and graphs must be attached in MS Excel (.xls, .xlsx) or vector format (.eps, .spv, .pdf) generated by statistical software. Decimal places in descriptions of axes or graph values must be presented as decimal points in accordance to European standards. Acceptable graph including background colours are shades of grey or flat black tone. Placement of full-colour figures or graphs is arranged by special request only. Figures and graphs in bitmap format with resolution under $300 \mathrm{DPI}$, or without graph source data, cannot be accepted.

\section{Abbreviations}

The first time an uncommon abbreviation appears it should be explained in parenthesis.

\section{References}

References (max. 30 for original research papers, max. 40 for review articles) should be typed in the order of their occurrence in the manuscript. Each reference must begin on a new line. All references cited should be quoted in the text with corresponding numbers in parenthesis. The Vancouver style of referencing is used in line with the recommendations of the International Committee of Medical Journal Editors: Uniform Requirements for Manuscripts Submitted to Biomedical Journals: Sample References, 2017): http:// www.nlm.nih.gov/bsd/uniform_requirements.html. References in a language other than English should be translated into English and followed by the original language in brackets for example (In Czech.).

\section{Legal and ethical aspects of publication}

All submissions must comply with basic ethical recommendations including data protection. Articles (text, tables and figures) must not compromise patient privacy. Do not present initials of patients, hospital or protocol numbers etc. The author is responsible for respecting the intellectual property rights of authors of data taken from other publications or sources. The Conclusion of a manuscript must carry a statement pertaining to support by any firm or sponsorship organization, names and numbers of grant projects and any conflict of interest where the author has direct or indirect interest in the results of manufacture or sale.

In the case of clinical studies the contribution should contain an affirmation of approval by a local ethics committee. If animal experiments are involved a declaration of adherence to constitutional or national guidelines and regulations for use of experimental animals is to be included.

\section{Information on publication in biomedical journals}

Uniform Requirements for Manuscripts Submitted to Biomedical Journals are available on the International Committee of Medical Journal Editors (ICMJE) website http://www.icmje.org/.

\section{Editing and proofs}

One set of page proofs in PDF format will be sent by email to the corresponding author. The proofs are done by the author, but no essential changes are permitted. The authors are requested to return the corrected proofs within 7 days after their delivery. Corrections of proofs will not be taken into consideration if they are not received on time. By confirmation of proofs the author agrees that the submitted work will be published and made accessible on the Journal website.

\section{Publication fees}

Manuscripts submitted after February 1, 2016 will be published in CEJPH on the understanding that the author(s) will pay a publication fee of 60 EUR excl. VAT per article at a maximum length of six published pages (up to approx. 5,800 words - the word count is for the manuscript text only). Each additional page is subject to a 60 EUR excl. VAT surcharge. Authors will be required to confirm at the time of submission that they agree to pay these charges in the event that their manuscript is accepted for publication. Payment instructions will be sent to authors prior to publication.

The corresponding author of papers will receive an issue of the Journal without special order free of charge. 